\title{
Evaluation of Quality Care for Senior Citizens in Primary Health Care
}

\author{
Tainara Lôrena dos Santos Ferreira1, Tiago José Barbosa de Andrade², \\ Janio Gustavo Barbosa ${ }^{3}$, Iris do Ceu Clara Costa4, Fábia Barbosa de Andrade ${ }^{1}$ \\ ${ }^{1}$ Nursing, Faculty of Health Sciences of Trairi (FACISA), Federal University of Rio Grande do Norte (UFRN), Santa \\ Cruz, Brazil \\ ${ }^{2}$ Student of Computer Science, University Center of João Pessoa (UNIPÊ), João Pessoa, Brazil \\ ${ }^{3}$ Developer of Virtual Environments, Federal University of Rio Grande do Norte (UFRN), Natal, Brazil \\ ${ }^{4}$ Department of Dentistry, Federal University of Rio Grande do Norte (UFRN), Natal, Brazil \\ Email: tainara lorena@hotmail.com, tiagobarbosajp@yahoo.com.br, janioguga@gmail.com, \\ iris odontoufrn@yahoo.com.br, fabiabarbosabr@yahoo.com.br
}

Received 1 September 2014; accepted 24 August 2015; published 27 August 2015

Copyright (C) 2015 by authors and Scientific Research Publishing Inc.

This work is licensed under the Creative Commons Attribution International License (CC BY).

http://creativecommons.org/licenses/by/4.0/

(c) (i) Open Access

\section{Abstract}

Objective: This study aimed to evaluate the quality care received by senior citizens in Primary Health Care (PHC) in the Unified Health System, with the objectives of contributing with the comprehensive implementation of humanized conduct and actions for this part of the population. Methods: This is a descriptive-exploratory study with a quantitative approach that was conducted in the city of Santa Cruz, which is located in the Brazilian state of Rio Grande do Norte, with a population of 130 senior citizens. The research was approved by the Committee for Ethics in Research at the Federal University at Rio Grande do Norte under protocol 152/2012. Results: In the results, the classification of the PHC services varied from good to reasonable. Regarding the assistance offered to the aging and comprehensive care, there were failures in accordance with how it's recommended in the National Healthcare System. This concludes, through the perspective of the elderly user, the need for the reformulation of the activities which are offered to this population and therefore the implementation of conduct for better service in the area of Primary Health Care.

\section{Keywords}

Quality of Life, Health of the Elderly, Nursing

\section{Introduction}

The increase in Brazil's senior citizen population reveals improvements in the health index of this group, and 
with this, it's proposed that access to health services is ensured at all levels of service and the execution of activities that aim for the promotion, protection and recovery of the health of this group which presents greater vulnerability to the onset of chronic diseases and big changes at the phase of life.

Aging was an important victory for humanity in the last century, but only the increase of senior citizens does not ensure dignity and quality of life. Brazil's aging population is a victory which results in demands by the aging population, in the context of the National Healthcare System [1].

Throughout the years, some people change their social lifestyle which isn't always very easy. There are simple activities that can be brought back such as excursions, trips, making new friends, taking courses, new interests and pleasures [2]. In this way, the health services that contemplate attention the health services network need to have professionals that are trained and sensitive for care of the aging work with equity, comprehensiveness and universality.

The function of health policies is to contribute so that more people can reach old age in the best state of health possible, aging actively and healthy being the main objective. To consider health in a more general way, a change in the current context towards the production of a social and cultural environment that is more favorable to the aging [1] population becomes necessary.

A healthy lifestyle is associated with increasing physical activities regardless if they are done in the workplace, commuting, leisure or domestic activities, and as a consequence, with higher standards of health and life [3]. It is known that each year that passes, people age with better health conditions and quality of life, meanwhile, often times this situation isn't maintained. Along with aging, comes retirement and many times, ostracism and social isolation [4].

Improving the quality of life of this part of the population, which is likely to grow in the upcoming years, is of great social value. The nurse and health staff should think about managing the activities, orientation, and the informal and family support that serve the specific necessities of the senior citizen [5]. Many challenges arise from an aging population, especially from a group that needs a system of protecting due to its vulnerability, which demands maintenance, expansion and the sedimentation of the victories of the Senior Citizens' Statute, with the objective of consolidating a Welfare State which makes citizenship [6] more effective.

In this sense, the Ministry of Health is establishing guidelines for healthy gaining in Brazil by investing in health services, strengthening Primary Health Care (PHC), training professionals to promote social projects and research focused on assistive technologies and social redemption for this population.

Understanding it like the health of the aging population presents itself an important client in the context of the community reveals the necessity for the participation of the health professional in continuous care in the Primary Health Care context in the participating community. In the interim, PHC is a gateway to the other levels of health focused on the care networks in such a way that this study's role in the proposal is to evaluate the importance of PHC professional assistance offered to the aging population through a user's perspective about the PHC network in the National Health care System.

\section{Methodology}

The study is descriptive-exploratory with a quantitative approach carried out from July to December 2012 in the city of Santa Cruz which is located in Rio Grande do Norte, Brazil, with a sample of 130 elderly, are using a non-probabilistic sample, to avoid unnecessary exposure of the elderly population.

This study is a clipping from the research entitled Atenção Primária à Saúde: um estudo de avaliação na perspectiva dos usuários (Primary Health Care: an evaluative study from a user’s perspective). The criteria were being a senior citizen with cognitive capacity intact, reside in the selected UBS community and sign an Informed Consent form. The parameters used for this study revolved around the care of attributes for the elderly, in order to investigate the health and quality of life.

The interviews were conducted by interviewers graduate students in nursing UFRN/FACIS entered previously trained using the instrument Primary Care Assessment Tool (the PCATool). The sample was not probabilistic and convenience, according to the criteria of inclusion and exclusion.

The interview was conducted on the environment and booked individually, after explaining the research objectives, as well as reading and signing the Informed Consent Form (ICF) by the subjects. Subjects were interviewed in PHC units distributed in the city of study. Interviews take place in reserved place at the Health Unit, where each interview took around thirty minutes. 
The results were inserted in the Statistical Package for the Social Sciences (SPSS), version 22.0, with serial number: 10101141047. To analyze the data, the average, median and standard deviation were calculated. In the context of bivariate analysis, chi-squared tests were performed, maintaining a level of significance less than 0.05 and Confidence Interval of 95\%.

The study followed all the regulations contained in the National Health Council Resolution 466/2012, regarding studies with human beings. The project was submitted and approved by the Ethics and Research Committee (CEP), of the Federal University of Rio Grande do Norte (UFRN), under number 152/2012.

\section{Results}

The results reveal that 92 (70.8\%) are women and 38 (29.2\%) men, with a minimum age of 60 and maximum of 96, an average of 72.8 years old; median of 72.0 and standard deviation of 8.3. As monthly family income was obtained mean of $\mathrm{R} \$ 740.1$ and median of $\mathrm{R} \$ 572.5$. As for education the average is 1.58 years studied, a median of 0.25 and standard deviation of 2.0.

As to the classification of PHC service from the user's viewpoint, $48.5 \%(n=63)$ claimed it was good; followed by 32.3\% $(n=42)$ reasonable; $6.9 \%(n=09)$ bad and lastly $6.2 \%(n=08)$ as excellent and horrible.

The data revealed a Cronbach Alpha of 0.91, in other words, $91 \%$ which reveals the existence of internal validity and reliable data in the construct. The Cochran test was even calculated, being significant with $\mathrm{p}=0.00$, also showing variance homogeneity. This shows that evaluation scale is feasible and reliable to be used in the PHC network to evaluate the service quality offered to the senior citizens.

In Table 1, the user responses regarding the reception before the consultations were $53.8 \%(n=70)$ stated that they are always received; $20 \%(n=26)$ frequently; and $17.7 \%(n=23)$ stating sometimes. It also makes reference about the invitation to the senior citizens by the health professionals to participate in senior citizens groups where $38.5 \%(n=50)$ reported they were never invited; 32.3\% $(n=42)$ sometimes; $15.4 \%(n=20)$ stated they always received an invitation. The data collected shows positive results, but on the other hand, the data on invitations to participate in senior citizens groups revealed low impacting results in relation to reception, showing an associated relation with $\mathrm{p}<5 \%$.

In Table 2, the user responses regarding the orientation received in health service. Regarding the orientation about healthy aging 38.5\% $(n=50)$ affirmed never received it; 30.8\% $(n=40)$ sometimes; $18.5 \%(n=24)$ verbalized frequently, showing a significant relation in the chi-squared test of $\mathrm{p}<5 \%$. As for the orientation received about prevention and control of chronic diseases 30.8\% $(n=40)$ reported that sometimes they had received recommendations; 29.2\% $(n=38)$ always received it; $20 \%(n=26)$ said frequently. This data showed a positive context in the evaluation of users whose correlation is significant with a chi-squared value of $\mathrm{p}<5 \%$.

Table 3 makes reference to the home visits conducted by health professionals to offer care to the senior citizens where $40.8 \%(n=53)$ of the interviewees sometimes received the visit; $35.4 \%(n=46)$ Never. When the existing correlation was analyzed, the service classification evaluation in PHC and the visits conducted, a value of $\mathrm{p}<5 \%$ was perceived.

Table 1. Correlation between the classification of service quality and reception by primary health care professionals before going in for the consultations and the invitation for users to participate in senior citizens groups. Santa Cruz, RN, Brasil, 2012.

\begin{tabular}{|c|c|c|c|c|c|c|}
\hline & Never & Rarely & Sometimes & Frequently & Always & $\mathrm{p}$ \\
\hline Reception before the consultation & $4.6 \%(n=06)$ & $3.8 \%(n=05)$ & $17.7 \%(n=23)$ & $20.0 \%(n=26)$ & $53.8 \%(n=70)$ & 0.027 \\
\hline $\begin{array}{l}\text { Invitation to participate in senior } \\
\text { citizens groups }\end{array}$ & $38.5 \%(n=50)$ & $8.5 \%(n=11)$ & $32.3 \%(n=42)$ & $5.4 \%(n=07)$ & $15.4 \%(n=20)$ & 0.000 \\
\hline
\end{tabular}

Table 2. Correlation between the classification of service quality and the orientation received from the profession staff about healthy aging, prevention and control of chronic diseases. Santa Cruz, RN, Brasil, 2012.

\begin{tabular}{|c|c|c|c|c|c|c|}
\hline & Never & Rarely & Sometimes & Frequently & Always & $\mathrm{p}$ \\
\hline Healthy aging & $38.5 \%(n=50)$ & $7.7 \%(n=10)$ & $30.8 \%(n=40)$ & $18.5 \%(n=24)$ & $4.6 \%(n=06)$ & 0.000 \\
\hline Chronic diseases & $14.6 \%(n=19)$ & $5.4 \%(n=07)$ & $30.8 \%(n=40)$ & $20.0 \%(n=26)$ & $29.2 \%(n=38)$ & 0.000 \\
\hline
\end{tabular}


Table 3. Correlation between the classification of service quality and home visits conducted by health professionals to senior citizens who can't take themselves to the services. Santa Cruz, RN, Brasil, 2012.

\begin{tabular}{ccccccc}
\hline & Never & Rarely & Sometimes & Frequently & Always & p \\
\hline Home visits & $35.4 \%(n=46)$ & $6.2 \%(n=08)$ & $40.8 \%(n=53)$ & $6.2 \%(n=08)$ & $11.5 \%(n=15)$ & 0.001 \\
\hline
\end{tabular}

\section{Discussions}

In this study there were gaps in the assistance offered by the Primary Health Care professionals to the interviewees since the frequency of "sometimes" followed by "Never" for services that comprise PHC, which shows the need for monitoring of this senior citizen in the primary network, proposing care guidelines that guided through the branches of care with the purpose of ensuring assistance rooted in the attributes of continuity and assistance longitudinality as pillars for offering quality assistance.

As shown in Table 1, reception of the elderly in PHC has been carried out, which complements service accessibility. It is known that reception strengthens the user-service relation and enables the development of health-related activities, integrating the elderly into the social environment and creating links with the community where they live and the health team in their area, which facilitate the execution of activities associated with the promotion, protection and recovery of health, diagnostics and monitoring activities.

Understanding about the quality of life, read in innumerous fields of knowledge: biological, social, political, economic, medical, among others in a constant interrelation [7]. The Primary Health Care, mainly in PHC, as a fundamental element to promote the adoption of a proper lifestyle, stimulate a balanced diet, practice regular physical activities, improve autonomy and independence of the aging person through the decrease chronic diseases and raising the quality of life of this population

Since the reception implies a humanized approximation of relations in the establishment, in the perspective of developing autonomy and their effectiveness is related with the utilization of available resources that adjust and vie for the resolution of the users' [8] problems. And, that good or bad quality service depends on the perception that the subject has about their biological and social existence being dependent on their activities and the environment around [7] them.

Humanizing the relationship with the user demands that the worker values affection and sensibility as elements necessary for care and that such a relationship doesn't apply an act of charity by the selfless professionals and people with essential human qualities, but an encounter between subjects, human beings, who con constructs a healthy relationship, sharing knowledge, power and life experience [9].

As for the participation of the senior citizen in groups formed at the PHC facility, Table 1, it was perceived that there is no significant way of strengthening the senior citizens' role in the facility and community. It is known that the cultural and community identity benefit the aging population because in addition to well-being, they promote new circles of friends, and increase the quality of life and self-esteem. In this way, the need to strengthen support and incentives from the professionals of cares based on stimulation and participation as co-participants in this permanent education process and active subjects of care in community health.

However, in Table 2, the orientation by the professionals was more present in the clinical focus. In other words, there is more about chronic diseases and less dialogue about healthy aging. But, this orientation always needs to be aligned in the agenda of health officials since the participation of the senior citizen in the care process is fundamental because along with valuing their autonomy, It favors the adoption of a healthier life since the senior citizen is a multiplying agent of knowledge, also adding their experience with the objective of a more decent quality of life.

The quality of life during old age is ample and intertwined with several personal and interpersonal factors, giving way to the importance of participation in group [6] activities. And that the elderly benefit a lot from healthy and decent aging, care, family protection, friendships, developing their pre-existing capacities and participating in society as useful citizens [6].

In this sense, the incentive for campaigns aimed primarily at raising awareness of the population to adopt healthier lifestyles is also an attitude that will only bring benefits to both the quality of life and autonomy of the elderly, strengthening the relationship between health and disease through the exercise [10].

It is noteworthy that the increase in life expectancy in the country, unhealthy eating practices and other factors associated with aging may facilitate the onset of chronic diseases senior citizens because it is a more vulnerable 
group, however, preventive measures can be taken reducing the occurrence of chronic diseases. Thus, the health professional's role is to encourage the elderly to prevent and control these diseases by advising them on healthier life styles.

Once we encourage prevention and the delay the occurrence of diseases, we are collaborating to preserve in the future, what we call functional capacity. With the rapid and intense aging of the Brazilian population, this becomes the new paradigm and the main strategic indicator on health [11]. This shows that having reduced functional capacity or damaging this, brings physical, social and economic impact on the family and society where this elderly is inserted.

Within the framework of conducting home visits to the elderly population, Table 3, it is known that the home visits become important since it favors professional knowledge of the social environment that the individual is inserted, knowing their reality more extensively, thereby being able to provide quality care ensuring continuity of assistance by a healthcare professional.

Home visiting is one of the activities planned for health professionals according to the operational norms of health care in the PHC network since it establishes that greater approximation to the reality of the user's problem occurs so that assistive intervention happens at the location where the senior citizen resides in cases of pathological and/or disabling conditions that prevent you from going to the health service.

Furthermore, it is necessary to remember that the daily demands of the PHC professionals are great and this requires attention, care and programming of continued assistance focused on comprehensiveness in such a way that activities are often hampered because of these demands.

Based on this understanding, the healthcare team responsible for the care of the senior citizens requires knowledge of the conditions of the health-related environment such as sanitation and housing which are of great relevance in establishing measures to promote quality of life of individuals, families and communities [12].

Thus, from the results presented it is understood that Primary Health Care plays a large part in the monitoring of $t$ health necessary for the elderly since it is the gateway to other levels of services and is closest to the population, broadly facilitating the perception of the subjects, strengthening the links and concept of family.

\section{Conclusions}

This study proposed to evaluate the importance of PHC professional assistance to the senior citizen population in the perception PHC users in the National Healthcare system and it revealed positive and negative aspects in the assistance received.

Regarding PHC services, it was seen as good to reasonable, which shows that the services need to be more prepared to receive the senior citizen users. This premise is to find what is proposed by the Ministry of Health when it establishes the Quality Improvement Program in the PHC network.

The professional monitoring of Primary Health is necessary and is very important during the aging process, however, continuous and effective monitoring is necessary, not only worrying about service access but also its quality.

Another aspect is the participation of professionals in offering quality care in PHC expected in quality orientation and home visits. These care professionals should promote health, health education focusing on disease control, maintenance and recovery, preserving functional capacity with the aim of a high quality of life.

Considering the important results shown in this study that reveal the quality of public health in Brazil, it is worth noting that the above has limitations because it is the elderly population, which has in its physical and psychic structure restrictions that have been observed in this study.

Through analyzed data, failure in the assistance offered to the senior citizen and comprehensive care, in accordance with how it's recommended in the National Healthcare System. This shows the necessity of the health teams to resume the operational guidelines proposed in the Pacto pela Vida when it offers implementation of activities for the aging population that are expanded, more inclusive and humanized.

We consider that the present study had some limitations, mainly because it is a local study and due to the need to adapt the instrument to local Brazilian reality. However, it allowed us to make some considerations about the assistance that is being provided to elderly people in the PHC network. Another important aspect in the quality evaluation process is the necessity to strengthen the National Primary Care Policies because the Brazil health model has a primary base with a strong following in the territory and community in such a way that the technical, operational and procedural conduct foreseen in this primary care base deserves to be implemented to strengthen the principles of the National Healthcare System—universality, equity and comprehensiveness. 


\section{References}

[1] Brasil. Ministério da Saúde. Secretariat of Health Care. Department of Programmatic and Strategic Actions (2010) Health Care for the Elderly and Aging. Technical Area Health of the Elderly, Brasília, 44 p. http://portal.saude.gov.br/portal/arquivos/pdf/volume12.pdf

[2] Celich, K.L.S. and Spadari, G. (2008) Health and Lifestyle: Conditions for Healthy Aging. Cogitare Enferm, 13, 252260. http://ojs.c3sl.ufpr.br/ojs/index.php/cogitare/article/view/12497/8559

[3] Toscano, J.J.O. and Oliveira, A.C.C. (2009) Quality of Life in Elderly Subjects with Different Levels of Physical Activity. Revista Brasileira de Medicina do Esporte, Niterói, 15, 169-173. http://www.scielo.br/pdf/rbme/v15n3/a01v15n3.pdf

[4] Souza, L.M. and Lautert, L. (2008) Voluntary Work: An Alternative to Promote Health for the Elderly. Revista da Escola de Enfermagem da USP, 42, 371-376. http://www.lume.ufrgs.br/bitstream/handle/10183/69673/000648286.pdf?sequence=1

[5] Faller, J.W., Melo, W.A., Versa, G.L.G.S. and Marcon, S.S. (2010) Quality of Life for Elderly Registered in the Family Health Strategy (FHS) of Foz do Iguaçu-PR. Escola Anna Nery, Out.-Dez, 14, 803-810. http://www.scielo.br/pdf/ean/v14n4/v14n4a21.pdf

[6] Hein, M.A. and Aragaki, S.S. (2012) Health and Ageing: A Study of Brazilian Masters Dissertations (2000-2009). Ciênc. saúde coletiva, Rio de Janeiro, 17, 2141-2150. http://www.scielo.br/pdf/csc/v17n8/24.pdf

[7] Almeida, M.A.B., Gutierrez, G.L. and Marques, R. (2012) Qualidade de vida: Definição, conceitos e interfaces com outras áreas de pesquisa. Escola de Artes, Ciências e Humanidades - EACH/USP, São Paulo, 142 p. http://each.uspnet.usp.br/edicoes-each/qualidade_vida.pdf

[8] Medeiros, F.A., Souza, G.C.A., Barbosa, A.A.A. and Costa, I.C.C. (2010) Basic Health Unit Embracement: Focusing on User Satisfaction. Rev. salud pública., 12, 402-413. http://www.scielosp.org/pdf/rsap/v12n3/v12n3a06.pdf http://dx.doi.org/10.1590/S0124-00642010000300006

[9] Casate, J.C. and Corrêa, A.K. (2005) Humanization in Health Care: Knowledge Disseminated in Brazilian Nursing Literature. Rev Latino-americana de Enfermagem. jan-fev, 13, 105-111. http://www.scielo.br/pdf/rlae/v13n1/v13n1a17.pdf

[10] Zago, A.S. (2010) Physical Exercise and Health-Disease Process in Elderly. Rev. Bras. Geriatr. Gerontol. Rio de Janeiro, 13, 153-158. http://revista.unati.uerj.br/pdf/rbgg/v13n1/v13n1a16.pdf

[11] Veras, R.P. (2012) Disease Prevention in the Elderly: Misconceptions in Current Models. Cad. Saúde Pública, Rio de Janeiro, 28, 1834-1840. http://www.scielo.br/pdf/csp/v28n10/03.pdf

[12] Azeredo, C.M., Cotta, R.M.M., Schott, M., Maia, T.M. and Marques, E.S. (2007) Assessment of Sanitation and Housing Conditions: The Importance of Home Visits in the Family Health Program Context. Ciênc. saúde coletiva, Rio de Janeiro, 12, 743-753. http://www.scielo.br/pdf/csc/v12n3/25.pdf 